\title{
Reconciling agile frameworks with IT sourcing through an IT sourcing dimensions map and structured decision-making
}

\author{
Fouad Amiri ${ }^{1}$ (D) Sietse Overbeek ${ }^{1}$ (D) $\cdot$ Gerard Wagenaar $^{1}$ (D) . \\ Christoph Johann Stettina ${ }^{2}$ (D)
}

Received: 5 December 2020 / Revised: 14 April 2021 / Accepted: 17 June 2021 /

Published online: 7 July 2021

(c) The Author(s) 2021

\begin{abstract}
While there is a plethora of literature on IT Sourcing (ITS) strategy, little is known about the impact of large-scale agile frameworks on these strategies. Empirical evidence suggests that application of agile frameworks has an impact on governance and processes in large organisations including ITS strategies. Yet, the effects of such frameworks remain unrevealed. This research investigates the impact of agile frameworks on ITS decisions and the way organisations configure their ITS strategies. The research first studies literature to realise that there is a lack of empirical research on ITS strategies in organisations that use agile frameworks. Then, through a systematic literature review, ten different dimensions of ITS are identified and used as the required construct for a multiple-case study at six Netherlands-based organisations. The results reveal that four dimensions, namely sourcing model, location, pricing model, and relational governance are mostly affected by agile frameworks. Furthermore, after more than three years of utilising agile frameworks, case organisations still have not discovered a proper optimum point for these dimensions. The results also uncover that organisations are not fully aware of the impact of agile transformation on the process of ITS decision-making. This process may remain intact for years, resulting in continuous experimentation and trial and error of ITS strategies. We conclude that organisations should recognise the effects of agile frameworks to make ITS decisions accordingly. Additionally, adhering to a more rational and structured decision-making process helps organisations to more efficiently find proper optimum points for the dimensions of ITS strategy.
\end{abstract}

Keywords Agile framework · IT sourcing strategy · IT sourcing decision-making process $\cdot$ IT sourcing dimension $\cdot$ Configuration-based approach

Fouad Amiri

fouad.amiri@gmail.com

Extended author information available on the last page of the article 


\section{Introduction}

IT Outsourcing (ITO) emerged in the mid-60s when hardware and IT services were not affordable to all companies (Lee et al. 2003). ITO has evolved and significantly altered ever since and has undergone several changes over the past decades (Lee et al. 2003; Vassiliadis et al. 2006). During these periods of transition, organisations started to massively rely on outsourcing in order to catch up with the changes in markets (Rust and Kannan 2003). As a recent example, using cloud computing has changed ITO mindset, enabled organisations to scale their outsourced solutions, increased business flexibility and facilitated globally distributed outsourcing (Dhar 2012; Pattnaik et al. 2016). Nowadays, ITO shapes on average around $20 \%$ of all IT expenditures of large organisations and falls under the more general term of IT Sourcing (ITS) (Hall et al. 2017).

While the first agile frameworks like Scrum appeared in the late 90s, large-scale frameworks such as SAFe emerged later in 2010s. Large-scale Agile frameworks like SAFe have not only an impact on the project layer, but also on the delivery of large multi-team initiatives such as SAP implementations, as well as the portfolio management layers (Stettina and Hörz 2015). Depending on the size and state of adoption, this can have a large impact on the organisational governance including supplier management and sourcing strategies. For example, through different contracting schemes (Zijdemans and Stettina 2014).

Sourcing involves different contextual factors, dimensions and determinants that result in completely different types of arrangements (Marcolin and McLellan 1998; Dibbern et al. 2004). The variety of possible arrangements of sourcing strategies has led to the advent of a relatively new set of approaches to designing sourcing strategies under the term of configuration based approaches (Cullen and Seddon 2004). However, there is still a need for more up-to-date empirical research into the ITS decision-making process and its outcome (i.e. ITS strategy) (Dibbern et al. 2004; Lacity et al. 2009; Westphal and Sohal 2016).

ITS implies that there is a degree which indicates the extension of outsourcing in comparison to insourcing in an organisation (De Looff 1998). Disruptions of the IT market have made ITS, a strategic decision for larger organisations during the past decades (Smith and McKeen 2004; Fjermestad and Saitta 2005; Mann et al. 2015). Many managers now consider ITS as a strategy to concentrate more on core competencies to achieve competitive edge (Hodosi and Rusu 2019). Therefore, nowadays, the role of an effective ITS strategy on the success of outsourcing in highly volatile and competitive business environments is more crucial than before (Sohel and Quader 2017).

Although around 94\% of companies have tried outsourcing at least once in their lifetime (Hall et al. 2017), around $25 \%$ to $50 \%$ of the outsourced IT projects fail (Hodosi and Rusu 2019). These failures are mostly caused by contingent decisionmaking and being slow to develop a comprehensive ITS strategy (Gottfredson et al. 2005). To help organisations avoid failures, a significant number of papers have been published. As an indication for the extent of overload, the term "sourcing strategy" returns 15,500 results in Google scholar. However, it is sometimes very difficult to 
draw a conclusion from these diverse and often conflicting prescriptions (Cullen et al. 2005b; Schoeman et al. 2008).

On the other hand, agile transformation has various effects on ITS (de Vries and Verkijk 2017; Gerster and Dremel 2019). Currently, larger organisations are widely adopting agile frameworks not only in their IT departments, but also in their business units (Gerster and Dremel 2019). 69\% of organisations have been undergoing agile transformation for less than three years (Business Agility Institute 2019) and $43 \%$ of large organisations in the Netherlands are willing to practice agile at enterprise scale (KPMG 2019). However, ITS arrangements are not properly classified and are scarcely studied considering this new wave of transformation.

In order to fill the empirical gap in the literature, our study aims to answer the following questions:

$R Q 1$ : What is the state-of-the-practice of configuring ITS strategies in large-scale organisations that use agile frameworks?

$R Q 2$ : What is the impact of agile frameworks on the configuration of ITS strategies?

RQ3: How can large-scale organisations align their ITS strategies with their agile frameworks?

Regarding RQ3, considering the moderate success rate of previous prescriptions, our study does not focus on prescribing a certain type of ITS arrangement; rather, it tries to facilitate the process of ITS decision-making by providing constructs and guidance that are extracted from the knowledge gained through answering RQ1 and RQ2.

This research has theoretical as well as empirical contributions. Through an systematic literature review (SLR), a map containing dimensions and elements of ITS strategy is defined. Based on this map and a multiple-case study, empirical insights into the state-of-the-practice of ITS strategy are gained and the impacts of agile frameworks on the dimensions of ITS are identified. In the end, through an analysis of the results, a set of suggestions are provided to allow organisations to define their ITS strategies more in alignment with their agile frameworks.

This paper is intended to present the findings in the following order: first, a brief theoretical background is provided in Sect. 2. Then, the research method is described in Sect. 3. The results of the SLR and the multiple-case study are presented in Sects. 4 and 5 followed by a discussion in Sect. 6. In the end, in Sect. 7, we conclude the research by answering the research questions and stating the limitations and suggestions for future works.

\section{Background}

Since this research studies the state of ITS strategies when utilising agile frameworks, it is as well important to review and define general terms and find the confluence of these concepts beforehand. 


\subsection{Large-scale agile frameworks}

Traditional agile practices are designed for a single or a few development teams and are not meant to become scalable (Boehm and Turner 2005). These methods are mostly applicable to smaller and co-located teams (Paasivaara 2017). Nowadays, all enterprises must learn how to adapt swiftly to changes using agile concepts, even for the ones that are not necessarily IT or software companies (Rosing et al. 2015). However, utilising agile software development methods in large organisations is complex and challenging and requires a special form of coordination (Dyba and Dingsoyr 2009). These challenges have led to the emergence of multiple extended derivations of traditional agile methods such as Scrum of Scrums (SoS), scaled agile framework (SAFe), Large Scale Scrum (LeSS), Spotify, etc. under the term of large-scale agile frameworks (Kalenda et al. 2018). These frameworks are more complicated than simple agile practices and target larger organisations. They also differ in the level of complexity, the agile methods that they use and the type of organisations they support.

Launching large-scale agile frameworks requires various changes in an organisation and publications usually explain the basics and less guidance can be found on how to handle particular situations (Conboy and Carroll 2019). Agile transformation at enterprise scale is a strategic decision and affects other organisational strategies as well (Heikkilä et al. 2017). Sourcing strategies within these frameworks are no exception. For instance, the main reference of SAFe explicitly bewares practitioners of extreme challenges of sourcing (Knaster and Leffingwell 2018). The sourcing strategy of IT services is an important aspect of an agile organisation and is continuously affected by the adoption of new agile practices. The sourcing strategy in an agile organisation includes different elements, such as scope, contracting and the pricing model, intention, location, governance, etc. These elements can be entirely affected by the type of agile practices in a large-scale organisation (Demirbas et al. 2018).

\subsection{IT sourcing strategy perspectives}

When designing a plan or strategy, especially in ITS, many different situational factors and uncertainties are involved which should be realised to mitigate the risks of failure (Clarke and O'Connor 2012). Apart from ITS situational factors, ITS also consists of a variety of dimensions and choices which result in a wide diversity of ITS strategies in different organisations (Marcolin and McLellan 1998; Dibbern et al. 2004; Cullen et al. 2005b). Depending on the extent of emphasis on the situational factors or on the dimensions when defining an ITS strategy, two different approaches have been proposed by scholars, namely contingency and configuration-based approaches.

\subsubsection{Contingency perspective}

In the contingency perspective, decisions are made based on situational factors (Meyer et al. 1993). In the context of ITS, the typical situational factors that are mentioned frequently in many publications are the firm, industry and market characteristics (Lee et al. 2004; Lacity et al. 2009). These factors can be classified into two 
major categories, namely internal factors and external factors. The goal of contingency is to limit the multi-dimensionality of environment by reducing the variety of these situational factors (Meyer et al. 1993). Therefore, in the contingency approach, the strategic view is narrowed down to a specific organisation and the focus is more on the situational factors involved in that particular case.

\subsubsection{Configuration-based perspective}

On the other hand, some researchers assume that the traditional contingency approach promotes the notion of oversimplifying things by removing the dimensions of decision-making (Miller 1981). In the configuration-based approach, it is tried to concentrate more on the multi-dimensional nature of ITS instead of solely focusing on the situational factors (Meyer et al. 1993). In general, while the contingency approach focuses mainly on the relationship between the context and the organisation, the configuration-based approach focuses more on the dimensions of ITS decisions and tries to find a fit between all of the dimensions that are involved in decision-making (Khandwalla 1972). Configuring and sorting things into homogeneous groups allow decision-makers to systematically interpret the reality and reduce complexity (Kluge 2000; Leimeister 2010). Researchers have also quantitatively pointed out that the configuration-based perspective is more effective when defining fitting ITS strategies than the contingency perspective (Lee et al. 2004). Therefore, the configuration-based approach is also followed in this paper.

\subsubsection{Key elements of IT sourcing strategy}

Configuration of ITS strategies is a form of strategic decision-making (Varajão et al. 2017; Damanpour et al. 2019). The situational factors and the dimensions of ITS decisions are two elements of strategic decision-making (SDM) (Rajagopalan et al. 1997). Beside these elements, the process of decision-making and configuring the dimensions is also another key aspect of reaching a fitting ITS strategy in configuration-based approach (Westphal and Sohal 2016). Interrelationships between these elements are shown in Fig. 1.

Dimensions of IT sourcing strategy: ITS strategy dimension, as a term, was first coined by Lee et al. (2003). ITS strategy dimensions are the variables that should be realised and defined to explain how high-level ITS strategies should be structured and configured. In other words, if we assume that the situational factors are the independent variables of an ITS decision-making process, the dimensions would be the dependent ones.

Although situational factors are well elaborate in the extant ITS literature by different scholars (Lacity et al. 2009; Arbogast et al. 2012; Gerster and Dremel 2019), ITS strategy dimensions are not covered properly by researchers. A few example of disparate and mixed up ITS dimensions that can be found in literature are the ones that are related to the duration of ITS contracts (Lacity et al. 2009), the ones related to the location of sourced projects (Gerbl et al. 2015) and the extent to which IT functions are outsourced (Hodosi and Rusu 2019). Therefore, in Sect. 4, we try to extract these sparsely available dimensions in literature by conducting an SLR. 


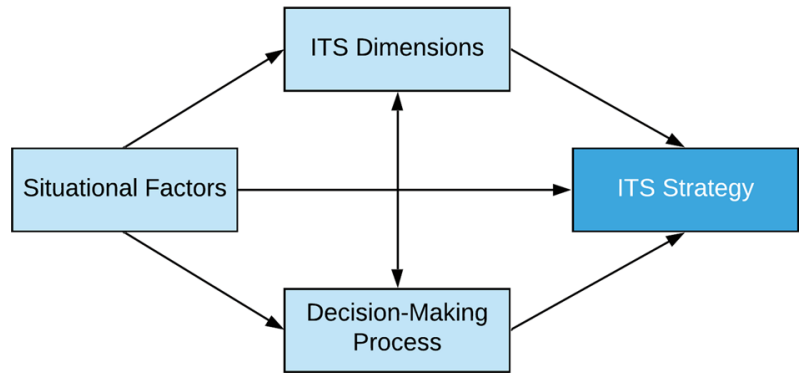

Fig. 1 SDM model of ITS strategies. Inspired by Bell et al. (1997)

Process of IT sourcing decision-making: ITS strategies must be configured properly in the decision-making phase before jumping into execution. But the way organisations come up with fitting values and approach decisions is another key element of ITS strategy. This key element is called the process of ITS decision-making and like the dimensions of ITS is not fully covered in literature (Westphal and Sohal 2016). To fill this gap, a recent study of four large Australian-based companies concludes that in order to efficiently define successful ITS strategies, the discovery process should be followed Westphal and Sohal (2016). The discovery process is a methodological approach to strategic decision-making and is not necessarily related to any specific type of strategy (Nutt 2011). The approach consists of four major phases and starts with a call for gathering intelligence and understanding the context followed by the search for possible options, evaluating the options and uncovering the final solution (Nutt 2008). However, the details of activities within each phase are missing in the extant literature and will be studied more thoroughly through an SLR in Sect. 4.2.

\subsection{IT Sourcing within agile frameworks}

As previously mentioned in Sect. 2.1, launching large-scale agile frameworks requires various changes in an organisation including different alterations in the way organisations source services. ITS strategy is also an aspect of sourcing which is on the one hand, more complex than any other types of sourcing (Patil and Wongsurawat 2015) and on the other hand, is mostly affected by the need to increase the speed and flexibility of agile frameworks (Dutta et al. 2017; Gerster and Dremel 2019). As an example, incorporating agility impacts IT contract types (Zijdemans and Stettina 2014), since long and precisely specified contracts might be replaced by modules sourced in small and iterative packages (Opelt et al. 2013). However, contracting is not the only ITS phase which is affected by agile frameworks. Since this study is focused on the strategic phase of ITS (i.e. the decision-making phase), we will mainly study the impacts of agile frameworks on ITS decisions. 


\section{Research methodology}

The research methodology to answer the questions of this research consists of two major phases. Since we need to collect an up-to-date list of ITS dimensions which can be used as a scaffold to answer the research questions, the first part of the methodology is done via an SLR to be able to systematically include all possible dimensions. The second phase is a multiple case study which seeks to find answers to the research questions based on the qualitative research outline of Yin (2017).

\subsection{Systematic literature review}

A literature review must be thorough and fair to hold a scientific value (Kitchenham 2004). To achieve an acceptable level of thoroughness and fairness, a systematic review should be considered when performing the literature review. The techniques that we use to perform such a systematic review are based on the suggestions of Kitchenham (2004). In the protocol of our SLR, we define two main facets for our inclusion decisions. These main facets are (IT) (out) sourcing strategy and agile. We do not exclude all non-IT research since the main theories of outsourcing apply to both IT and non-IT contexts. Moreover, in some papers, the general term of sourcing strategy is used for sourcing IT services and non-IT services interchangeably. However, papers that are related to procurement as in the process of buying goods, performing non-IT projects, commodity procurement, supply chain or logistics are excluded. When searching for papers around the subject of agile, we only include the papers that are about (out) sourcing, distributed software development and Business-IT Alignment (B/IA). For instance, papers about transformation or how to become agile are excluded. When studying empirical research, we exclude case studies of smaller organisations since they are mostly concentrated on operational and executive challenges. However, some papers include multiple case studies of both small and large-scale organisations which are included as a source.

\subsubsection{Databases}

Different databases are used in order to collect the related literature. Google Scholar covers most of the famous scientific databases (e.g. Science Direct, ACM, IEEE) which is used mainly in this research. Sourcing is a multidisciplinary subject; therefore, it is essential to cover different domains of study such as managerial, business and computer science databases at the same time. In addition to Google Scholar, DBLP which is a computer science literature reference and the Web of Knowledge (ISI) which provides a comprehensive data citation reference of multiple scientific databases are used as well.

\subsubsection{Searches}

Based on the results of some preliminary searches, we can highlight the main search terms and keywords that are common in the domain of ITS. Moreover, semantic 
differences can also be realised in the preliminary search. For instance, we find out that in some papers, the term strategic sourcing is different from the main target of this research which is sourcing strategy. Strategic sourcing entails a wider scope and subjects such as details of contractual settings and relationships with vendors. At this stage, synonyms of the keywords are also detected and tried when searching. The main terms that are used in literature regarding the previously mentioned facets are IT sourcing method, IT sourcing practices, IT outsourcing methods, IT sourcing strategies, IT procurement strategy, large scale agile, sourcing strategies, outsourcing in agile, agile outsourcing, and agile outsourcing practices. We also construct search strings using Boolean's AND's and OR's.

\subsubsection{Study selection}

Apart from the main exclusion criteria which are previously explained, we also filter out some of the included literature. Since none of the studies had their focus directly on the subject of this research, we followed the techniques of Dikert to exclude irrelevant papers (Dikert et al. 2016). During the primary study stage, we read abstract sections of the identified papers and if relevant, conclusion sections as well. After that, we assign a score between one to 10 to each study. The score goes higher if these sections have a couple of paragraphs about sourcing strategy or they contain a few sentences about relationships between agile transformation and sourcing strategy or if there is at least one situational factor or ITS dimension mentioned. The paper scoring procedure is done by the main researcher of the paper but the guideline and also the outcomes are revised continuously by other authors as well. The selected papers to be further read are mainly among the ones that get a score higher than five in the preliminary study. In total, 901 papers that were selected in the primary search were filtered out to 324 papers in the initial filtering phase and after reading the abstract and conclusions sections. This number was reduced to 169 after full-text filtering when papers were fully read and graded. In the end, 74 best-graded papers were selected to shape the core of the literature review.

\subsection{Multiple-case study}

Case study is a relevant and proper technique if the questions of research seek to explain how or why some phenomenon happen (Yin 2017). Scholars are also frequently calling for more in-depth and qualitative studies in the domains of sourcing and strategic decision-making (Nutt 2008; Westphal and Sohal 2016). In this study, we use the qualitative research outline of Bell et al. (2018) alongside the case study approach of Yin (2017) to structurally conduct the research.

\subsubsection{Sampling}

We followed the purposive sampling technique to select samples that share particular characteristics and have the potential to provide rich, relevant and diverse data pertinent to the research question (Tong et al. 2007). The purposive sampling of this 
research is done with the help of the experts who already have experience in working with client organisations. Snowballing sampling procedure is also used within a case organisation in order to find more relevant and willing participants.

\subsubsection{Selection criteria}

Since the focus of this research is on large-scale organisations that use agile frameworks, the cases should also be large. An organisation that uses agile practices can be considered large-scale if it is shaped of at least 50 people or six teams (Dikert et al. 2016). Besides, since the organisations that follow waterfall or bimodal practices are in nature different from those that are agile (Horlach et al. 2017), we only select the organisations that have already utilised and established large-scale agile frameworks. We also focus on the organisations that have been practising agile for more than three years to guarantee that they have a decent level of maturity (Mersino 2018). We also filter out the organisations that are not intensively dependent on IT services or projects, meaning that in the case organisations, IT is used as a capability enabler or a way to rationalisation (Nordström et al. 2000). Different measures may be used to assess IT intensity of an organisation such as IT budget, number of tools and IT devices, penetration of software tools, number of staff active in IT, etc (Ali and Green 2005). Since IT is intertwined with many aspects of an organisation, we refined the list of IT intensive organisations based on their self claim in an initial inquiry. The list of the filtered organisations is presented in Table 1.

We can classify all key roles involved in the process of ITS decision-making into three groups, namely decision initiators (e.g. IS executives and top managers), decision-makers (e.g. senior executives and IS managers), and decision framers (e.g. IS managers and consultants) (Dibbern et al. 2004). Considering the fact that agile practices are commonly bottom-up approaches (Conboy et al. 2010), we can assume that at least two interviews at two different levels within an organisation are required. One of the interviews should be on the intersection of strategic and tactical levels (decision-makers) and the other one can be between the tactical and the operational levels (decision framers and executors). Participants can be senior executives, procurement managers, program or project managers, product owners and team leads. Besides, since some of these roles may be fully outsourced or the access to the client may be limited, if possible, interviews

Table 1 List of the cases

\begin{tabular}{lllllll}
\hline Code & Sector & Agile Exp. & Framework & Outreach & \# of Staff & Revenue (EUR) \\
\hline C1 & Finance & 4+ years & Spotify & Global & 40,000 & $12 \mathrm{~b}$ \\
C2 & Electronics & 4+ years & SAFe & Global & 20,000 & $11 \mathrm{~b}$ \\
C3 & Automotive & 3+ years & SAFe & Europe & 1000 & $2 \mathrm{~b}$ \\
C4 & Energy & approx. 3 years & SAFe & NL & 4000 & $1 \mathrm{~b}$ \\
C5 & Finance & 5+ years & SAFe & Global & 18,000 & $20 \mathrm{~b}$ \\
C6 & Energy & 6+ years & SAFe & Europe & 3000 & $6 \mathrm{~b}$ \\
\hline
\end{tabular}


with one of the partner vendors of each case are conducted to better explore the context and compensate for the lack of information from the client's side. The list of the interviewees is presented in Table 2. Three interviewees had years of background in both the client's organisation as well as the vendor's and they considered themselves as an employee of both organisations.

\subsubsection{Data collection}

We choose a semi-structured interview guideline with open-ended questions in order to enable interviewees to freely talk about their experience and to improve the effectiveness of theory extraction from the interviewee's experience (Schultze and Avital 2011). All interviews are recorded and transcribed to be coded at later stages. Interviews last between 30 and 60 min including the closing questions and open discussions.

At this stage, findings from a multi-vocal study are also taken into consideration and if possible, data is backed by the evidence found in literature. Furthermore, available details of some outsourced contracts of the case organisations are found on the internet and are compared with the interviewees' responses. This approach will allow us to make use of data triangulation and strengthen our findings (Creswell and Poth 2016).

Table 2 List of the interviewees

\begin{tabular}{lllll}
\hline Code & Organisation & Role & Experience with agile & Vendor/client \\
\hline P11 & C1 & Team lead (multiple teams) & 6+ years & Vendor \\
P12 & C1 & IT transformation manager & 7 years & Client \\
P13 & C1 & Project lead & 9 years & Vendor \\
P14 & C1 & Scrum master & 5+ years & Vendor \\
P15 & C1 & Program manager & 5 years & Client \\
P21 & C2 & IT procurement manager & 5+ years & Client \\
P22 & C2 & Deal execution manager & 4+ years & Vendor \\
P31 & C3 & Program lvl agile coach & 3+ years & Vendor \\
P32 & C3 & Delivery lead & 10+ years & Both \\
P33 & C3 & Team lead & 10+ years & Client \\
P41 & C4 & Program manager & 2+ years & Client \\
P42 & C4 & Senior procurement manager & 5+ years & Client \\
P43 & C4 & Scrum master & 5+ years & Vendor \\
P51 & C5 & Lead of transformation & 6+ years & Vendor \\
P52 & C5 & Agile transformation lead & 10+ years & Both \\
P53 & C5 & Delivery lead & 5+ years & Vendor \\
P54 & C5 & Head of IT sourcing & 4+ years & Client \\
P61 & C6 & Lead of transformation & 6+ years & Vendor \\
P62 & C6 & Delivery lead & 6+ years & Both \\
\hline
\end{tabular}




\subsubsection{Data analysis}

To facilitate the analysis of the transcripts, we use NVIVO. We also make use of two different coding classification techniques in NVIVO, namely initial and emergent. Therefore, the categories of codes may change as we analyse more interviews which is a common method of analysis (Saldaña 2015). All transcripts are read three times and coding is done during the second and the third runs. To increase the reliability of the coding system, codes that are created in the second run are compared to the ones in the third read and the differences are pointed out and resolved (Syed and Nelson 2015). However, both codings are done by the same researcher but in at least two weeks time span between each read.

Based on the suggestions of scholars, the analysis of the results of the interviews is divided into two major parts: the within-case analysis and the cross-case analysis (Eisenhardt 1989). After analysing each interview, a complete picture of the stateof-the-practice of ITS strategy is drawn for each case organisation. Then the crosscase analysis allows us to find patterns between the cases (Mathison 2005).

\section{Results of the systematic literature review}

During the preliminary literature review, it was realised that information about two major key elements of ITS decision-making which are at the centre of attention when following the configuration-based approach is disperse in literature. To collect and demonstrate this scattered information, an SLR is conducted. The results of this SLR is presented in this section.

\subsection{Dimensions of IT sourcing strategy}

Previously, scholars have extracted some of the main ITS dimensions from the extant literature (Cullen and Seddon 2004; von Jouanne-Diedrich 2004; Demirbas et al. 2018); however, since the focus of our study is on realising how agile organisations arrange these dimensions, we require a comprehensive, exhaustive and upto-date list.

Overall, 10 main dimensions are highlighter in the identified literature which are shown in Table 3. An extra dimension called exit plan was also suggested in a few papers (Hopwood 2018; Fitzgerald et al. 2017); however, considering the low number of mentions and the nature of an exit plan which is in essence different from other dimensions, it is not included in the list of dimensions. The list of the final best-graded papers and the dimensions that are mentioned in each article are also demonstrated in Table 4.

We take advantage of a special technique called concept matrix in order to synthesis the literature review findings and demonstrate them on the table (Webster and Watson 2002). The selected papers either classify ITS strategy dimensions or elaborate on a few particular dimensions and their attributes. Different naming 
Table 3 List of ITS dimensions

\begin{tabular}{lll}
\hline Dimension & Description & Code \\
\hline Vendor construction & The number of vendors involved in the project & D1 \\
Degree of outsourcing & The percentage of the budget allocated to outsourcing & D2 \\
Duration & The average duration of the contract & D3 \\
Ownership & Which party owns the intellectual property & D4 \\
Pricing model & The framework of billing in contract & D5 \\
Relational governance & The extent of trust and ties with vendor & D6 \\
Scope & Subject of outsourcing & D7 \\
Location & The location of vendor(s) & D8 \\
Intention & The purpose of sourcing & D9 \\
Sourcing model & Explains the distribution of responsibility & D10 \\
\hline
\end{tabular}

is proposed for each dimension and attributes within each dimension in the focal papers; however, we have tried to assign the most frequent titles to the dimensions and their attributes. There are also some dimensions that are mentioned only in a very few papers but are not included in this list. For instance, the chronology of sourcing is only mentioned by Von Jouanne-Diedrich which is not included in our list of dimensions (von Jouanne-Diedrich 2004). Furthermore, various attributes are suggested for some of the dimensions but we have selected the most frequent attributes. For instance, there are many different hybrids or innovative pricing models available in the extant literature but we only mention the most common ones.

Among the extracted dimensions, intention and scope are in essence different since they can be arranged even before the whole process of decision-making begins. The intention of outsourcing is usually determined when general business strategies are defined based on the available outsourcing theories (Nordigården et al. 2014). The scope is also usually identified when the business case is outlined. However, both of these dimensions should be fully recognised and properly set to efficiently define ITS strategies.

In order to better demonstrate all of the dimensions, we present the list of ITS dimensions in Table 5. The demonstrated list of ITS dimensions is also reviewed and slightly revised by a group of 10 expert practitioners to unify the terminology and the title of the dimensions with the ones that are being used in practice.

\subsection{Process of IT sourcing decision-making}

Apart from the research mentioned in Sect. 2.2.3, a few other scholars have also tried to partially identify the steps that should be taken when configuring ITS strategies (McIvor 2000; Dibbern et al. 2004; Kazmi et al. 2018). Different activities and sub-activities are suggested by these researchers in order to structurally make sourcing decisions. We listed then modelled the main decision-making activities of each of these papers to be able to compare them. This comparison is shown in Fig. 2. The technique used in order to demonstrate these activities is called process-deliverable diagrams (PDDs). This special notation is normally used to easily demonstrate all 
Table 4 Concept matrix of the ITS dimensions in scientific papers

\begin{tabular}{|c|c|c|c|c|c|c|c|c|c|c|}
\hline Article & D1 & D2 & D3 & D4 & D5 & D6 & D7 & D8 & D9 & D10 \\
\hline Demirbas et al. (2018) & $x$ & $x$ & $x$ & & $x$ & $x$ & $x$ & $x$ & $x$ & \\
\hline Hopwood (2018) & $x$ & & $x$ & $x$ & & $x$ & & $x$ & $x$ & $x$ \\
\hline Cullen et al. (2005a) & $x$ & $x$ & $x$ & $x$ & $x$ & $x$ & $x$ & & & $x$ \\
\hline Leimeister (2010) & $x$ & $x$ & & $x$ & & & $x$ & & & $x$ \\
\hline Schoeman et al. (2008) & $x$ & $x$ & $x$ & $x$ & $x$ & & $x$ & & & \\
\hline Könning et al. (2018) & $x$ & & $x$ & & & $x$ & $x$ & $x$ & & $x$ \\
\hline Derksen (2013) & $\times$ & & $x$ & & $\times$ & $x$ & $x$ & & $x$ & \\
\hline Fitzgerald et al. (2017) & & & & & & $x$ & $x$ & $\times$ & $x$ & \\
\hline von Bary (2018) & $\times$ & $x$ & $x$ & $x$ & & & & $x$ & & \\
\hline Lacity et al. (2009) & & $\times$ & $\times$ & & $\times$ & $\times$ & & & $x$ & \\
\hline Al-Ahmad and Al-Oqaili (2013) & $x$ & & & & & $x$ & & $\times$ & $x$ & \\
\hline Hyder et al. (2004) & $x$ & $\times$ & & & & & & & $x$ & $x$ \\
\hline Lee et al. (2003) & $x$ & $x$ & $x$ & $x$ & & & & & & \\
\hline Lee et al. (2004) & & $x$ & $x$ & $x$ & & $x$ & & & & \\
\hline Dibbern et al. (2004) & $x$ & $x$ & & $\times$ & & & & & & $x$ \\
\hline von Jouanne-Diedrich (2004) & $\times$ & $x$ & & $x$ & & & & $\times$ & & \\
\hline Hodosi and Rusu (2019) & $x$ & $x$ & & & & & & & & $x$ \\
\hline Gerbl et al. (2015) & & & & $x$ & & $\times$ & & & $\times$ & \\
\hline Gerster et al. (2018) & & & $x$ & & & $x$ & & $x$ & & \\
\hline Dutta et al. (2017) & $\times$ & $\times$ & & & & & & $\times$ & & \\
\hline Mahnke et al. (2005) & $x$ & & & & $\times$ & & & & $x$ & \\
\hline Su et al. (2016) & $x$ & & & & & & & & $x$ & \\
\hline Aris et al. (2008) & $x$ & & & & & $x$ & & & & \\
\hline Pratap (2014) & $x$ & & & & & $x$ & & & & \\
\hline Simmonds and Gilmour (2005) & & & & & & $x$ & & & $x$ & \\
\hline Varajão et al. (2017) & & & & & & & & $\times$ & $x$ & \\
\hline Nordigården et al. (2014) & & $x$ & & & & & & & $x$ & \\
\hline Fjermestad and Saitta (2005) & & & & & & & & & $x$ & \\
\hline Ali and Green (2012) & & & & & & $x$ & & & & \\
\hline Ågerfalk and Fitzgerald (2008) & & & & & & & & $x$ & & \\
\hline Pries-Heje and Pries-Heje (2014) & & & & & $x$ & & & & & \\
\hline Babin and Saunderson (2016) & & & & & & $x$ & & & & \\
\hline Count & 19 & 14 & 11 & 10 & 7 & 16 & 7 & 11 & 14 & 7 \\
\hline
\end{tabular}

activities as well as the outcomes of activities. A PDD consists of two parts: processes on the left-hand side, which is based on a UML activity diagram, and deliverables on the right-hand side, which is based on a UML class diagram (van de Weerd et al. 2006). However, in this Figure, we have skipped the deliverable side in order to maintain readability. Furthermore, sub-activities are also skipped to keep the simplicity of demonstration; therefore, following the guideline of the PDD technique, all main activities are sown as closed complex ones. 
Table 5 ITS strategy dimensions and their corresponding options

\begin{tabular}{ll}
\hline Dimension & Options \\
\hline Relational governance & Transactional, partnership \\
Sourcing model & Managed service, managed Capacity, staff augmentation \\
Location & Offshore, nearshore, onshore/onsite \\
Scope & Infrastructure, IS/applications, end-user management, security \\
Ownership & Client owns IP, joint venture, vendor owns IP \\
Degree of outsourcing & Total insourcing, selective, total outsourcing \\
Pricing model & Fixed price, time \& material (T\&M), payment per sprint \\
Duration & Long, medium, short \\
Intention & Focus on core capabilities, access to skills, innovation, cost \\
& reduction, improvement \\
Vendor construction & Multi vendor, single vendor \\
\hline
\end{tabular}

By comparing the main activities of the aforementioned methods, we observe some similarities with the concept of the discovery process. Therefore, we can classify the steps proposed in those papers under the main phases of the discovery process. The main phases of the discovery process are also shown in Fig. 2 as blue boxes .

\subsection{Impacts of agile frameworks on decision-making}

As discussed before, ITS strategies need to be configured through a set of activities within the decision-making phase (Westphal and Sohal 2016). Therefore, the impacts of agile frameworks on ITS strategies can be classified into the impacts on the results of the decision-making process (i.e. ITS configuration and sourcing guideline) and the impacts on the process of decision-making and the way decisions are made. Although realising the effects of establishing large-scale agile frameworks on both of these areas will help decision-makers to properly adjust ITS strategies when transforming into agile, these impacts are not covered well in the extant literature. In the next section, we try to identify these impacts through a multiple-case study and portray the state-of-the-practice of ITS decision-making.

\section{Results of the multiple-case study}

In total, 19 interviews are conducted within case organisations of this study plus eight interviews with experienced freelance consultants to gain more insights into the subject matter. Furthermore, one interviewee was the lead of transformation at organisation $\mathrm{C5}$ as well as C6; therefore during the interview, both organisations were covered. In addition to these interviews, two pilot interviews and multiple introductory interviews with experts are conducted before the official interviews. These introductory interviews led to multiple adjustments to the interview guideline including the improvement of overall clarity of the questions, interview time, and 


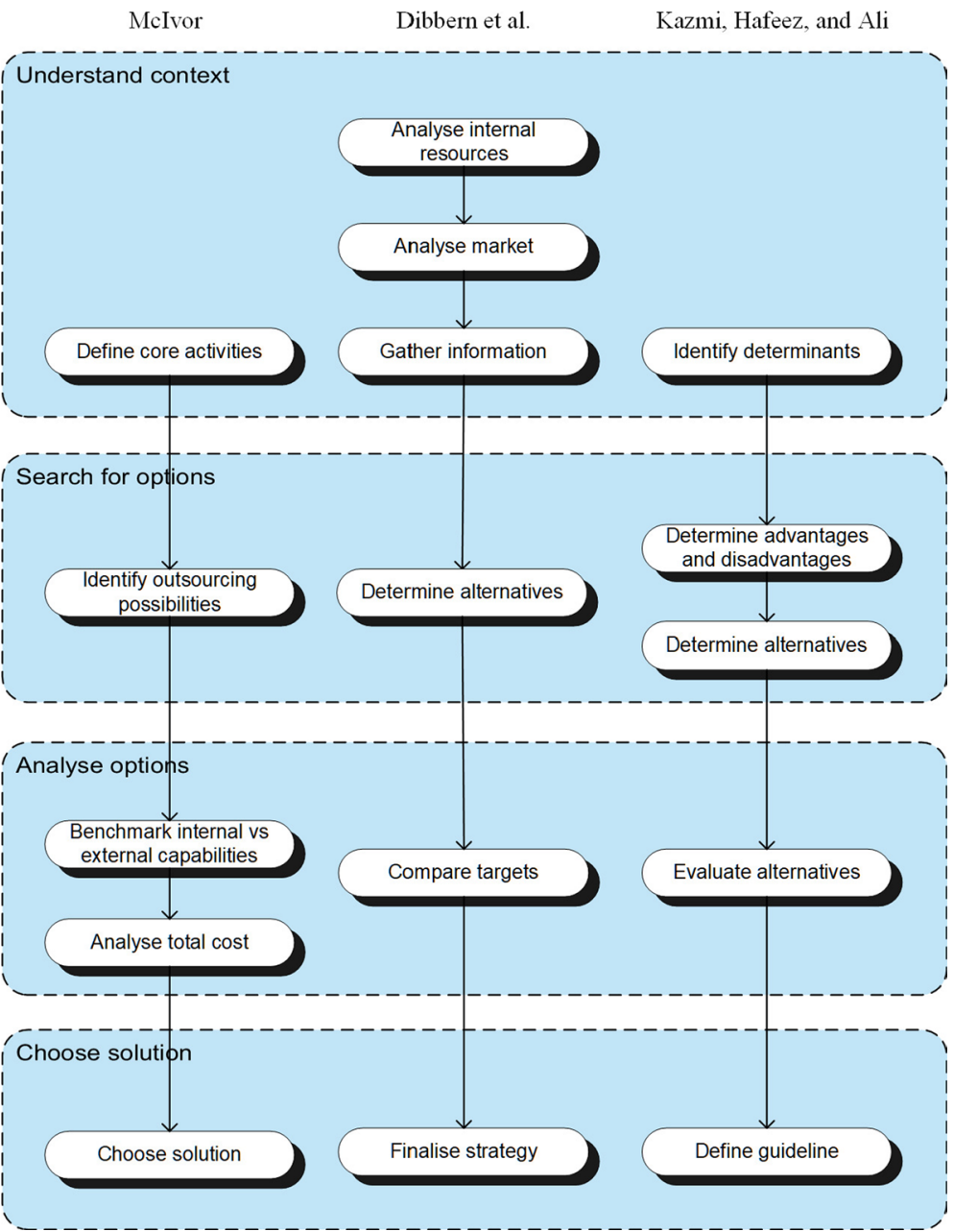

Fig. 2 Comparison of three different ITS decision-making processes proposed by McIvor (2000), Dibbern et al. (2004), and Kazmi et al. (2018)

tools that can be used in order to collect data especially regarding the map of ITS dimensions.

\subsection{Cases and descriptive variables}

\subsubsection{Industry attributes}

The influence of industry attributes on ITS decisions is not clear (Lacity et al. 2009); therefore the cases in this study are selected from different sectors to maintain generalisability. Regarding the financial stability, all cases are in good financial health. Organisations C3 and C6 are also part of bigger organisations and are supported by 
their parent companies. Additionally, in all cases, ITS decisions are strategic ones with a high level of complexity.

\subsubsection{Size attributes}

Size of an organisation may impact ITS decisions and larger organisations may follow more strategic paths of decision-making (Westphal and Sohal 2016; Drechsler and Weißschädel 2018). Therefore, we selected the cases with more than 1,000 staff. The level of decentralisation of the organisation may also impact strategic decisionmaking (Westphal and Sohal 2016). All cases' main headquarters are located in the Netherlands but the outreach of the cases vary in order to maintain generalisability.

\subsubsection{Attributes of the agile way of working}

In all case organisations but $\mathrm{C} 4$, agile practices have been in place for more than three years. Another fact about the level of agility in case organisations is that they have started the implementation of agile frameworks from bottom-up and first in a few departments and then scaled up the practices or are in the process of scaling up.

In organisations $\mathrm{C} 4$ and $\mathrm{C} 5$, the interviewees and especially the procurement team members still perceive agility as a means for the development teams only.

Agile in our organisation is mostly within the development team and not organisation-wide (P42).

In some cases, especially in vendors' opinion, it is believed that the agile way of working is not being applied efficiently or organisation-wide. P51 says "I would classify these organisations as agile in the name. They adopt a lot of ceremonies and processes but they do not take on a lot of what is necessary for the improvement". This pattern is seen in C2 and C4 as well. However, implementing an organisationwide agile framework is a continuous journey that never ends (Maples 2009). What is perceived as mature agile may differ from the vendor's to the client's perspective and that is why in this study, the overall age of agile frameworks is considered as the main indicator.

\subsection{Case analysis}

As mentioned before, the impact of agile frameworks on ITS decisions is twofold. On the one hand, agile frameworks may have an impact on the outcome of the decision-making process (i.e. the ITS configuration) and on the other hand, they may influence the process of decision-making. Therefore, each interview transcript is analysed individually. Firstly, to depict the current status of the organisation regarding ITS configurations and the process of defining ITS strategies. Secondly, to figure out the impacts of establishing agile frameworks on each of them from the interviewee's perspective.

In general, almost all interviewees were aware of the current status of ITS configurations in their organisations but some interviewees were not able to elaborate on 
the impacts of agile frameworks on the process of decision-making. This was mostly because some interviewees were not involved in the process of decision-making or decisions were already made before their entrance.

\subsubsection{State of IT sourcing configuration}

The concepts of ITS configuration-based approach are being applied in all cases and all interviewees were familiar with the elements of the ITS dimensions list. Considering the results in each case organisation, the most frequently observed attributes of each dimension are shown in Fig. 3 which is inspired by the way von JouanneDiedrich (2004) portrayed his dimensions list. The attributes which are observed in more than $50 \%$ of the case organisations are considered as most frequent. In five dimensions, namely degree of outsourcing, relational governance, vendor construction, ownership and duration, cohesive choices are observed among almost all cases. The diversity of choices is the highest within the intention of outsourcing dimension. However, cost reduction is observed as the main driver of outsourcing in almost all cases.

Apart from the intention of outsourcing, the sourcing model, the pricing model and the location of outsourcing are also three dimensions with the most mixed answers among cases. All organisations but $\mathrm{C} 4$ are trying at least one type of managed models of outsourcing alongside staff augmentation.

We are moving from staff augmentation to managed capacity and we want to push to managed services (P32).

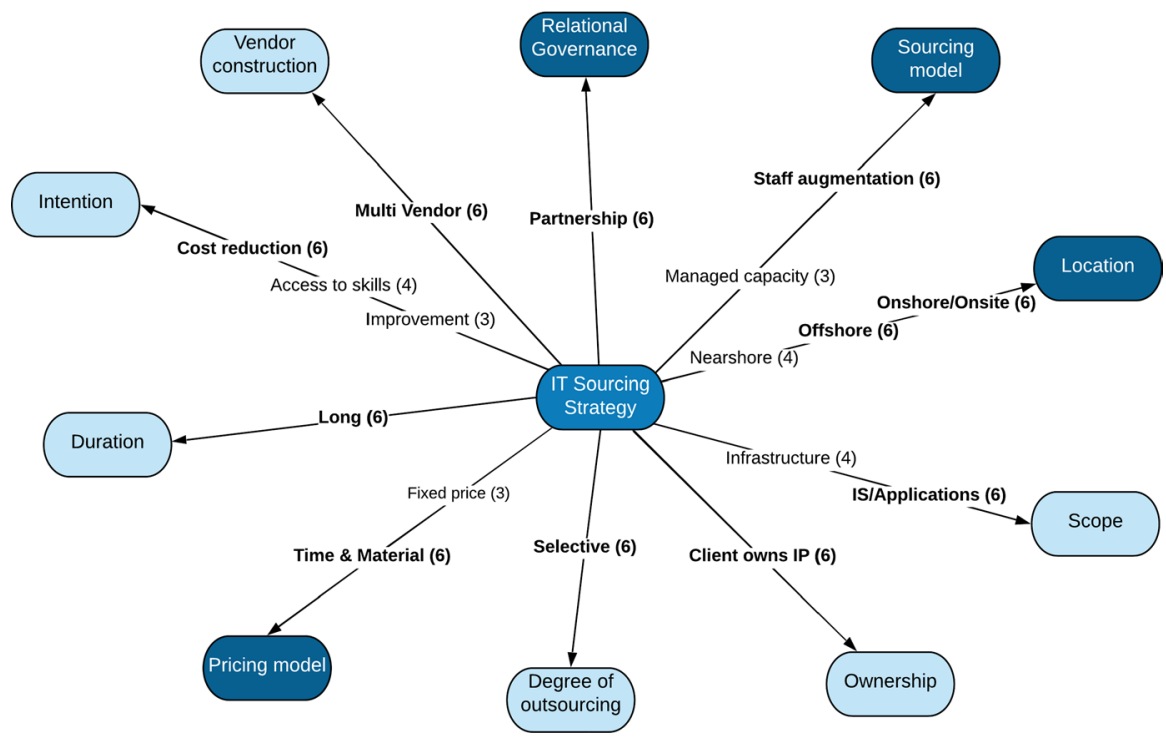

Fig. 3 The prevalent ITS configuration among cases portrayed in the map of ITS dimensions. The numbers indicate the number of cases using the attribute. Darker blue indicates the dimensions impacted by agile frameworks (colour figure online) 
Likewise, except in $\mathrm{C} 4$ - which is the least developed organisation in terms of agile transformation, all other organisations are trying to maintain a balance in the location of outsourcing. Regarding the pricing model, no particular pattern is observed but some of the case organisations are attempting to make use of fixed-price contracts besides T\&M.

The impacts of agile frameworks on the choices that are made when configuring ITS strategies are most evident on the location of outsourcing and the sourcing model which are mentioned in four cases, the relational governance and the pricing model are also mentioned in three cases followed by the degree of outsourcing which is mentioned in only one case. The same pattern of results is also seen if we consider the frequency of mentions among interviewees. The distribution of the claimed impacts of agile frameworks on ITS strategies is shown in Fig. 4.

\subsubsection{State of decision-making process}

The ITS process in almost all cases consists of three main stages, namely decisionmaking, contracting and execution. However, the interviewees could not provide a clear picture of how ITS-related decisions are made in the first phase. These decisions were either in place for many years with only minor changes from time to time or they were made at higher levels of organisations among CxOs. Based on the interviews, it is observed that the process of defining ITS strategies mostly follows the path of the organic model of strategic planning in which the vision and the values are of more importance than the process and the plan. Nevertheless, the main steps of the discovery process are partially taken in some organisations. In most cases, this decision-making approach has remained intact for many years. Thorough and continuous analysis of the current situation or the available options is sometimes skipped or is handed over to partners. This causes inconsistency in decision-making, different experimentation and swinging between choices within dimensions.

A couple of years ago, we started a new wave of outsourcing. Before that, we had a period of five years that we were turning everything back (P12).

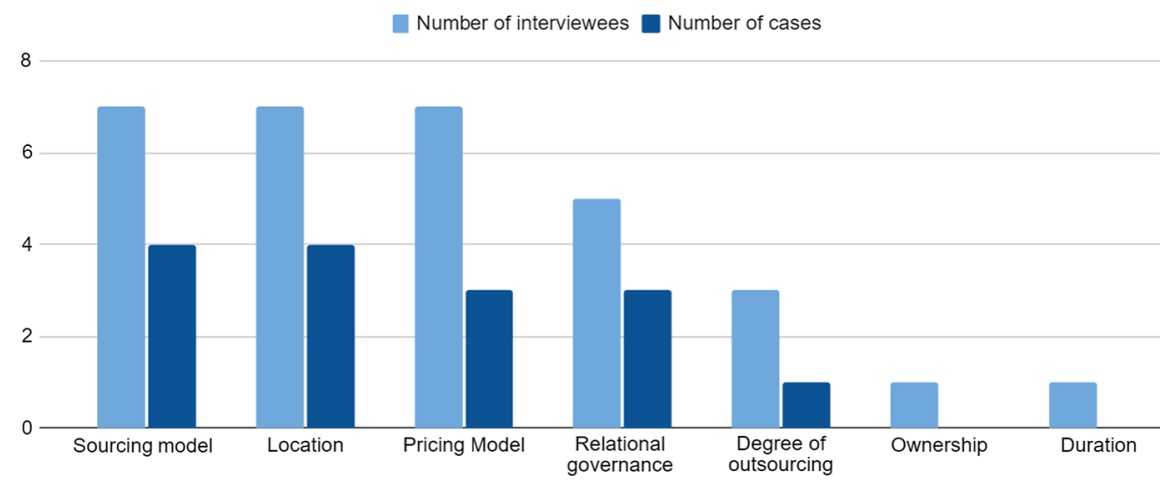

Fig. 4 ITS dimensions impacted by agile frameworks: observed among cases 


\subsubsection{Other observed patterns}

Our case organisations are predominantly benefiting from the collaboration of different vendors. An analysis of more than 1,000 ITO deals in Germany, Austria, and Switzerland shows that the multi-vendor type of ITS is on the rise with around 1.5 vendors actively participating on the same deal (Könning et al. 2018). In a multi-vendor setting, some of our case organisations are currently assigning projects to different vendors with different types of contracts at the same time which eventually causes conflicts. For instance, a partner with T\&M-based contract is currently working beside a vendor with a fixed-price plus bonus contract. This is observed in both $\mathrm{C} 1$ and $\mathrm{C} 6$ cases.

[...] has a contract which is $\mathrm{T} \& \mathrm{M}$ and can deliver people and [...] has a contract which is managed by the performance of the teams and then it does not really match (P62).

As a result of these conflicts, vendor consolidation is also observed in some cases. For instance, in $\mathrm{C} 1$, there is now a tendency towards limiting the number of vendors. P11 indicates "More or less, they are doing it end-to-end and trying to limit the number of vendors and give one task to one vendor". This can also be seen in C2, C4, C5 and C6. P54 states "We are doing multi-vendor [...] but our preference for vendor construction is to work with one vendor in one specific area". Vendor consolidation as well affects relational governance in some cases. It is sometimes believed that relational governance is partnership on paper but transactional in reality.

They mention that it is a partnership but sometimes it feels more transactional (P22).

Although all cases are predominantly using staff-augmentation as their sourcing model at the moment, they are shifting their sourcing models into using more managed models. This can be observed in all cases except in $\mathrm{C} 4$ and it is mentioned by at least one interviewee per each case. A similar pattern has already been predicted by Beulen (2018) in a distributed survey among large-organisations in the Dutch market.

\section{Discussion}

By using the map of ITS dimensions, we could easily portray the state-of-thepractice of ITS strategies in our case organisations and pinpoint the impacts of agile frameworks on each dimension. The patterns observed among cases regarding the choices that are made and the way these choices are approached lead us to three major observations. Firstly, our results indicate a conflict between the drivers of agile and outsourcing is clear in the results. Secondly, it is seen that the impacts of agile frameworks change the balance in particular dimensions and 
organisations struggle to find the optimum choice within those dimensions. In the end, it is observed that there is a lack of proper constructs and methods to systematically determine possible choices, understand the impacts and make decisions. These three observations are discussed in detail in this section.

\subsection{There is a conflict of incentives}

By reviewing the case study results, it is eminent that some choices within some dimensions are incongruent among cases. These dimensions are intention, sourcing model, location, and pricing model.

Agile values emphasis on the quality, the flexibility and the customer-centricity of services (Rosing et al. 2015). Cost efficiency is not at the centre of attention when practising agile (Gill and Henderson-Sellers 2006). Agile practices may even lead to deterioration of cost (Suetin et al. 2016). Therefore, cost reduction as the main intention of outsourcing among our cases is different from the other intentions of outsourcing which are more in alignment with agile (e.g. improvement of quality). This reason may justify the mixed answers that are given regarding the intention of outsourcing.

The location of outsourcing is another incohesive dimension. In a survey distributed among Dutch agile organisations in 2017, it was predicted that the location of outsourcing and the pricing model of sourcing strategies are going to be revised in three years due to the implications of agile transformation (Beulen 2018). However, regardless of what these implications are and which configuration would the best, such research proves that these dimensions require a special attention when making sourcing decisions.

Agile frameworks advocate insourcing and the distance and its subsidiary challenges such as temporal and socio-cultural differences are the most challenging issues in distributed agile (Ghafoor et al. 2017). Although outsourcing to offshore locations enables cost reduction and access to capabilities, it contradicts agility. The same pattern is also observed in sourcing model and pricing model dimensions. Staff augmentation and T\&M are both more agile in nature than their counterparts (i.e. managed models and fixed-price model). All of these three dimensions are also claimed to be impacted by agile frameworks. In general, there seems to be a conflict between agility and outsourcing and organisations are struggling to find a balanced fit when configuring ITS dimensions.

\subsection{Impact of agile changes the balance}

We can observe great similarities between the list of the dimensions which are mostly impacted by agile frameworks and the list of the dimensions that have incongruent choices. It can be perceived that the impacts of agile frameworks may have resulted in unbalanced choices within these ITS dimensions. Moreover, organisations are subconsciously seeking to find the best choices for these dimensions by doing experimentation and trial and error. 
Organisations at any point must realise that there is an optimum point between the attributes of each ITS dimension (balance perspective) and these optimum points must be set considering internal and external factors (fit perspective) (Kotabe et al. 2008). However, establishing agile frameworks significantly changes this balance and organisations need to adjust ITS strategies according to this disruption. These disruptions and the struggle to find an optimum point are also observed among our cases. Multiple interviewees highlighted the fact that they are moving back to the choices that were made a few years ago or they have found out that the choices need continuous adjustment but this adjustment is currently being done in a trial and error format. Avoiding such random experimentation and back and forth between choices can be achieved by first, recognising the dimensions of ITS strategies and contextual factors. Second-as previously touched upon by Westphal and Sohal (2016), by adhering to a formalised decision-making process in order to structurally assign values to each dimension. While finding the optimum point for some dimensions seems to be straight forward, in the dimensions which are mostly affected by agile frameworks, this task is a long course of trial and error if not done structurally. Location of outsourcing, sourcing model and pricing model are three main dimensions that should be at the centre of attention when sourcing IT services in organisations that use agile frameworks.

\subsection{More guidance is required in practice}

As previously evaluated by researchers, the adoption of a method which is based on the Discovery Process is more likely to generate the results that ITS decisionmakers are hoping to achieve (Westphal and Sohal 2016). However, a structured method could not be observed among cases when defining ITS strategies. The lack of a proper structure may lead to excessive work when seeking for optimum points within dimensions. The case organisations are still struggling to find these optimum points even after more than three years of practising agile frameworks.

We argue that organisations can benefit from the list of ITS dimensions presented in Table 5 to identify the decisions that should be made when configuring ITS strategies. Identifying decisions and possible options to these decisions will help organisations to structurally find a balanced fit among all dimensions. Neglecting a dimension or an option may completely change the balance; therefore, this map allows organisations to comprehend all possible dimensions and choices. Moreover, following a methodological approach such as the Discovery Process may allow organisations to more efficiently find the optimum point of ITS. Continuous analysis of the current situation and continuous elicitation of possible options and evaluation of the options is a way of discovering the balanced fit without relying too much on experimentation. Whilst going through the Discovery Process may take longer than ad-hoc decision-making - which is mostly triggered by an opportunity, at a minimum, it enables organisations to learn from choices and their consequences; therefore, reduces the amount of experimentation. The revised version of the Discovery Process which is demonstrated in Fig. 5 can help agile organisations more efficiently find the optimum point of their ITS strategy. This model comprises the 


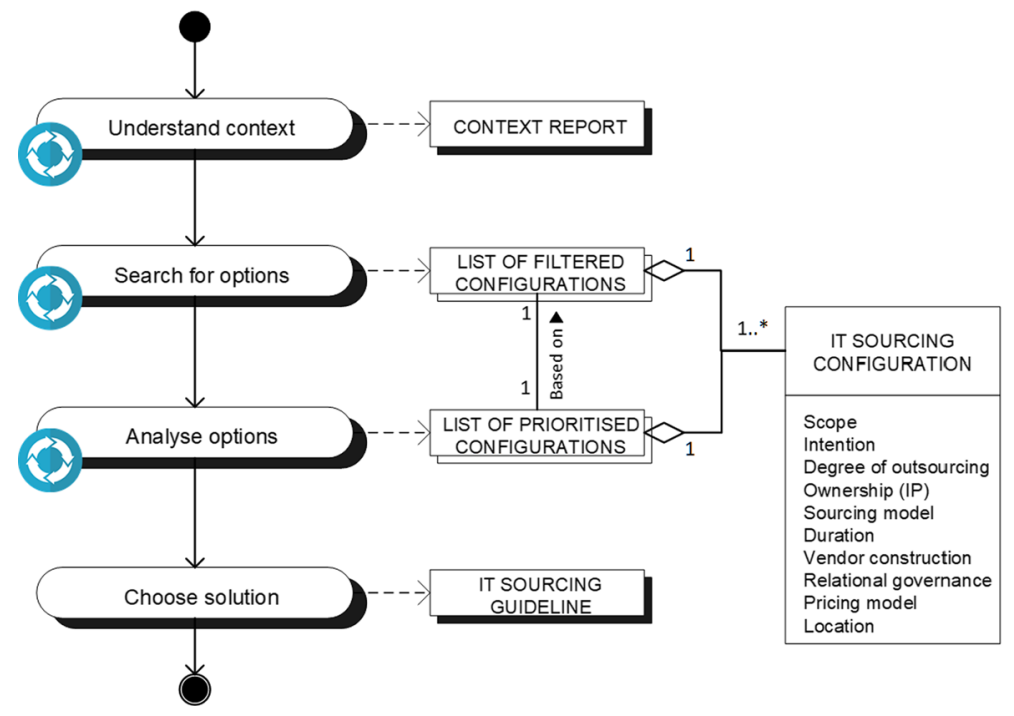

Fig. 5 Revised version of the discovery process

main phases of the Discovery Process and the major outcome of each phase as explained in Sect. 4.2. We avoided including sub-activities in this model in order to allow decision-makers to be able to follow a structured path and the same time to have the freedom of organic planning as explained in Sect. 5.2.2. However, at any point, activities within each phase can be selected among the set of activities shown in Fig. 2. The proposed model is also validated by four practitioner experts as a potential solution to the aforementioned issues. According to the practitioners, although the major phases of the revised Discovery Process can be applied to reallife cases, sub-activities within each phase cannot be determined beforehand considering differences in sourcing business cases.

\subsection{Limitations and validity threats}

We faced a few limitations and validity threats in our multiple-case study which we tried to mitigate using alternatives. Firstly, enormous amount of effort was put to reach out to managers and decision-makers; however, due to the strict set of selection criteria, we have based our study on a convenience sample to be able to conduct the study.

Regarding the external validity, the focus of this research was on the Dutch market; however, multiple complimentary interviews were conducted with experts outside of the Netherlands to assess the applicability of the results in other markets. Three interviews with experts portrayed relatively the same pattern among large organisations in India.

Another critical factor that limits the generalisability of the research is the usage of large-scale agile frameworks within case organisations. The results cannot be postulated for organisations that are not applying an agile framework at enterprise 
scale. Furthermore, five out of six case organisations of this study use SAFe as their agile framework which represents the popularity of SAFe among other frameworks as pointed out in reports (VisionOne 2020). However, we tried to keep the findings applicable to other frameworks by maintaining the neutrality of the questions.

Furthermore, all interviews from the vendor's side were conducted in one particular consulting firm. This will result in two concerns. First is that all case organisations were common in working with at least one particular vendor. Second is that the vendor's perspective is representative of one consulting company and not all existing vendors in the market. However, since the interviews with the vendor were considered to be supplementary interviews to gain more insights, we assigned higher weights to the answers given by the internal staff of the case organisations.

And in the end, although the map of ITS strategy dimensions and the revised version of the Discovery Process have been validated and adjusted by a group of experts during the research, it is important to mention that both require further investigations and evaluation in real-life cases to be proven just.

\section{Conclusions and future research}

In this paper, we investigated the state-of-the-practice of ITS strategy configuration and the impacts of agile frameworks on this configuration in large-scale organisations. The contribution of the study is multi-fold. First, it was realised that an exhaustive and up-to-date list of ITS dimensions is not available in literature; therefore, through an SLR, we identified the main ITS dimensions and their corresponding attributes. These dimensions should be arranged before the contracting phase of the ITS process is started. The final version of the map of ITS dimensions was also used as an instrument in our case study to structurally identify the state-of-thepractice of ITS strategies in case organisations.

$R Q 1$ : What is the state-of-the-practice of configuring ITS strategies in largescale organisations that use agile frameworks?

We conducted 19 interviews and covered six large-scale Dutch organisations that use agile frameworks to find out what decisions are being made regarding ITS strategies. The results of the interviews confirmed that the cases follow the configuration-based approach to define their ITS strategies. Furthermore, it was observed that the cases' ITS strategy configurations conform to the map of ITS dimensions. A similar pattern of decision-making was also seen among cases. In most of the dimensions, choices were cohesive; however, some dimensions represented mixed choices. Apart from intention and scope which are in essence different, the main incongruent dimensions were the location, the pricing model, and the sourcing model. Organisations were unable to find a balanced point within these dimensions and the choices were not decisive; therefore, they were subject to change.

$R Q 2$ : What is the impact of agile frameworks on the configuration of ITS strategies? 
Moreover, the results of the case study revealed that four dimensions are mostly affected by agile frameworks. These dimensions are location, pricing model, sourcing model, and relational governance. It became apparent that even after more than three years of practising agile, organisations are still struggling to find the proper arrangement for the dimensions that are most impacted by agile frameworks.

The results of the case study showed that organisations are aware of the possibility of disruptions caused by agile frameworks. They are also trying to adapt their ITS strategies to these disruptions. However, they are not fully aware of the fact that these changes may also impact the process of decision-making. The current process is based on the discovery process of strategy making and has not changed for years. Steps of this process are also not clear to the participants even at higher levels. Moreover, some decisions are made in an ad-hoc way. As a result, in almost all cases, experimentation is based on trial and error. Within the dimensions that are mostly affected by agile transformation, the decisions change without proper analysis; therefore the optimum points within these dimensions are still not found.

$R Q 3:$ How can large-scale organisations align their ITS strategies with their agile framework?

Outsourcing, which is predominantly driven by the intention to reduce cost is in contrast with the main principles of agile. Therefore, organisations should pay extra attention to the dimensions which are located on the intersection of the interests of agility and sourcing (i.e. location, pricing model, sourcing model, and relational governance). In order to find a balance between agility and sourcing in the aforementioned dimensions, organisations should first, be able to identify the decisions that need to be made and follow a structured path of decision-making. Second, organisations should adapt this path to agile frameworks and their flexible nature.

During the interviews, it was realised that organisations are to some extent aware of "what" should be decided (i.e. the dimensions of ITS strategy) and also they know that agile transformation may have an impact on this decision-making. However, in most cases, they did not know "how" to make that decision structurally or more importantly "how" to do that considering their agile transformation.

We proposed two separate instruments in order to address these concerns. Organisations will be able to define their ITS strategies more structurally by using the map of ITS dimensions. In this way, organisations know that what dimensions should be configured and they also know that which of these dimensions need to be adjusted according to their agile frameworks. However, values that should be assigned to each dimension (i.e. the outcome of the decision-making process), require further analysis and should be based on the ever-changing contextual factors.

To do such analysis systemically, based on the findings of our SLR, we propose a method for ITS decision-making which is shown in Fig. 5. This method is the adjusted form of the Discovery Process which is a famous method of strategic decision-making. By using a proper decision-making method, organisations will be able to continuously diagnose the current situation and recognise situational factors. Then they can analyse available options and find possible configurations for ITS dimensions. Finally, they will evaluate these possible options to properly find an optimum point within each dimension. By performing such an structured analysis, 
organisations can avoid experimentation when configuring ITS strategies. Furthermore, in order to adapt better with the nature of agile frameworks, organisations need to continuously loop over the steps and adjust configurations based on the most recent changes in the environment. This process may be resource consuming; nevertheless, focusing mostly on the critical dimensions, namely location, pricing model, and sourcing model will reduce the complexity of this process and increase the applicability.

In the end, it may be required to mention that this research did not aim to suggest a prescription of a determined sourcing configuration for agile organisations. Rather we tried to inform such organisations about the importance of following a structured path when making sourcing decisions and to provide them with tools and instruments to freely adjust these decisions according to their need.

\subsection{Future research}

The results and the limitations of this research give opportunities for more extended research in several directions.

Traditional methods of working have been in place for many decades. The stateof-the-practice of ITS in traditional organisations has deviated significantly in different eras of outsourcing. To better assess the impacts of agile frameworks on ITS strategies, a comparative study in this area would also be helpful. Samples of such studies could be divided into four groups of traditional, bimodal, immature agile, and mature agile large organisations.

Moreover, this research was performed in the Dutch market. However, as pointed out by one of the experts during the validation phase, the results may slightly be different in other markets, especially in North America. Distance from the major go-to places of outsourcing and cultural differences may lead to different sourcing decisions; therefore, further studies are required to enable generalisability of the results of this research.

Funding This paper is the result of the Master's thesis of the first author in the Department of Information and Computing Sciences at Utrecht University and a research internship at Accenture.

Data Availability Statement The recordings of the interviews are destroyed as mentioned in the interview consent form. However, the anony-mised transcripts and the codings plus the NVIVO project files are available to be shared per request.

\section{Declarations}

Conflict of interest The authors declare that they have no conflict of interest.

Open Access This article is licensed under a Creative Commons Attribution 4.0 International License, which permits use, sharing, adaptation, distribution and reproduction in any medium or format, as long as you give appropriate credit to the original author(s) and the source, provide a link to the Creative Commons licence, and indicate if changes were made. The images or other third party material in this article are included in the article's Creative Commons licence, unless indicated otherwise in a credit line to the material. If material is not included in the article's Creative Commons licence and your intended use is 
not permitted by statutory regulation or exceeds the permitted use, you will need to obtain permission directly from the copyright holder. To view a copy of this licence, visit http://creativecommons.org/licen ses/by/4.0/.

\section{References}

Ågerfalk PJ, Fitzgerald B (2008) Outsourcing to an unknown workforce: exploring opensurcing as a global sourcing strategy. 32(2):385-409

Al-Ahmad W, Al-Oqaili A (2013) Towards a unified model for successful implementation of outsourcing and reversibility of information systems. J King Saud Univ-Comput Inf Sci 25(2):229-240

Ali S, Green P (2005) Determinants of effective information technology governance: a study of IT intensity. In: Proceedings of the international IT governance conference, Auckland, New Zealand

Ali S, Green P (2012) Effective information technology (IT) governance mechanisms: an IT outsourcing perspective. Inf Syst Front 14(2):179-193

Arbogast T, Larman C, Vodde B (2012) Agile contracts primer. Agile Contracts http://www.agilecontr acts.org

Aris S, Arshad NH, Mohamed A (2008) Conceptual framework on risk management in IT outsourcing projects. Management 36(37):37-38

Babin R, Saunderson S (2016) Governance of outsourcing: building a better relationship. J Inf Syst Appl Res 9(1): 16

Bell E, Bryman A, Harley B (2018) Business research methods. Oxford University Press, Oxford

Bell GG, Bromiley P, Bryson J (1997) Spinning a complex web: links between strategic decision making context, content, process, and outcome. In: Strategic decisions. Springer, pp 163-178

Beulen E (2018) Implementing and contracting agile and devops: a survey in the Netherlands. In: International workshop on global sourcing of information technology and business processes. Springer, pp 124-146

Boehm B, Turner R (2005) Management challenges to implementing agile processes in traditional development organizations. IEEE Softw 22(5):30-39

Business Agility Institute (2019) The business agility report, 2nd edn., vol 1. Business Agility Institute (2019). https://businessagility.institute/download/2019-business-agility-report/

Clarke P, O'Connor RV (2012) The situational factors that affect the software development process: towards a comprehensive reference framework. Inf Softw Technol 54(5):433-447

Conboy K, Carroll N (2019) Implementing large-scale agile frameworks: challenges and recommendations. IEEE Softw 36(2):44-50

Conboy K, Coyle S, Wang X, Pikkarainen M (2010) People over process: key people challenges in agile development. IEEE Softw 28(4):48-57

Creswell JW, Poth CN (2016) Qualitative inquiry and research design: choosing among five approaches. Sage publications, p 256-263

Cullen S, Seddon P (2004) Configuration: an important concept for understanding IT outsourcing. In: Pacific-Asia conference on information systems.

Cullen S, Seddon P, Willcocks L (2005a) Managing outsourcing: the life cycle imperative. MIS Q Exec 4(1):229-246

Cullen S, Seddon PB, Willcocks LP (2005b) IT outsourcing configuration: Research into defining and designing outsourcing arrangements. J Strateg Inf Syst 14(4):357-387

Damanpour F, Magelssen C, Walker RM (2019) Outsourcing and insourcing of organizational activities: the role of outsourcing process mechanisms. Public Manag Rev 22(6):767-790

De Looff LA (1998) Information systems outsourcing: theories, case evidence and a decision framework. In: Willcocks L, Lacity M (eds) Strategic sourcing of information systems. Wiley, Chichester, UK, p 249-281

Demirbas U, Gewald H, Moos B (2018) The impact of digital transformation on sourcing strategies in the financial services sector: evolution or revolution? In: The 24th Americas conference on information systems, New Orleans, USA

Derksen B (2013) Impact of IT outsourcing on Business and IT alignment. Vrije Universiteit, Amsterdam

Dhar S (2012) From outsourcing to Cloud computing: evolution of IT services. Manag Res Rev 35(8):664-675 
Dibbern J, Goles T, Hirschheim R, Jayatilaka B (2004) Information systems outsourcing: a survey and analysis of the literature. ACM SIGMIS Database: DATABASE Adv Inf Syst 35(4):6-102

Dikert K, Paasivaara M, Lassenius C (2016) Challenges and success factors for large-scale agile transformations: a systematic literature review. J Syst Softw 119:87-108

Drechsler A, Weißschädel S (2018) An it strategy development framework for small and medium enterprises. Inf Syst e-Bus Manag 16(1):93-124

Dutta DK, Gwebu KL, Wang J (2017) Strategy and vendor selection in IT outsourcing: is there a method in the madness? In: Global sourcing of services: strategies, issues and challenges. World Scientific, pp 451-477

Dyba T, Dingsoyr T (2009) What do we know about agile software development? IEEE Softw 26(5):6-9

Eisenhardt KM (1989) Building theories from case study research. Acad Management Rev 14(4):532-550

Fitzgerald B, Stol KJ, Minör S, Cosmo H (2017) Scaling a software business: the digitalization journey. Springer, Cham

Fjermestad J, Saitta JA (2005) A strategic management framework for IT outsourcing: a review of the literature and the development of a success factors model. J Inf Technol Case Appl Res 7(3):42-60

Gerbl M, McIvor R, Loane S, Humphreys P (2015) A multi-theory approach to understanding the business process outsourcing decision. J World Bus 50(3):505-518

Gerster D, Dremel C (2019) Agile contracts: learning from an autonomous driving sourcing project. In: The 27th European conference on information systems (ECIS), Stockholm and Uppsala

Gerster D, Dremel C, Kelker P (2018) Agile meets non-agile: implications of adopting agile practices at enterprises. In: 24th Americas conference on information systems, New Orleans

Ghafoor F, Shah IA, Rashid N (2017) Issues in adopting agile methodologies in global and local software development: a systematic literature review protocol with preliminary results. Int J Comput Appl 160(7):37-41

Gill A, Henderson-Sellers B (2006) Measuring agility and adaptibility of agile methods: a 4 dimensional analytical tool. In: The IADIS international conference on applied computing 2006. IADIS Press

Gottfredson M, Puryear R, Phillips S (2005) Strategic sourcing. Harv Bus Rev 83(2):132-139

Hall L, Futela S, Gupta D (2017) IT key metrics data 2017: key industry measures. Tech. rep., Gartner Research Report

Heikkilä VT, Paasivaara M, Lasssenius C, Damian D, Engblom C (2017) Managing the requirements flow from strategy to release in large-scale agile development: a case study at Ericsson. Empir Softw Eng 22(6):2892-2936

Hodosi G, Rusu L (2019) Risks, relationships and success factors in IT outsourcing: a study in large companies. Springer

Hopwood MN (2018) Effective strategies for managing the outsourcing of information technology. PhD thesis, Walden University

Horlach B, Drews P, Schirmer I, Böhmann T (2017) Increasing the agility of IT delivery: five types of bimodal IT organization. In: Proceedings of the 50th Hawaii international conference on system sciences

Hyder EB, Heston KM, Paulk MC (2004) The esourcing capability model for service providers (escmsp) v2, part 1: model overview. In: Information technology services qualification center (ITSQC). Carnegie Mellon University, Technical Report No CMU-ISRI-04-113

Kalenda M, Hyna P, Rossi B (2018) Scaling agile in large organizations: Practices, challenges, and success factors. J Softw Evol Process 30(10):e1954

Kazmi SHM, Hafeez Y, Ali S (2018) Software outsourcing model for risk mitigation. In: 2018 international conference on computing. mathematics and engineering technologies (iCoMET). IEEE, pp $1-11$

Khandwalla PN (1972) Environment and its impact on the organization. Int Stud Manag Organ 2(3):297-313

Kitchenham B (2004) Procedures for performing systematic reviews. Keele, UK, Keele Univ 33(2004):1-26

Kluge S (2000) Empirisch begründete typenbildung in der qualitativen sozialforschung. Forum Qual Soz $1: 1$

Knaster R, Leffingwell D (2018) SAFe 4.5 distilled: applying the scaled agile framework for lean enterprises. Addison-Wesley Professional

Könning M, Westner M, Strahringer S (2018) Multisourcing on the rise: results from an analysis of more than 1000 IT outsourcing deals in the ASG region. In: Proceedings of the multikonferenz wirtschaftsinformatik, pp 06-09 
Kotabe M, Murray JY, Mol MJ (2008) Global sourcing strategy and performance: a "fit" versus "balance" perspective. In: international business scholarship: AIB fellows on the first 50 years and beyond. Emerald Group Publishing Limited

KPMG (2019) Survey on agility. Agile transformation: from agile experiments to operating model transformation: how do you compare to others?, vol 1. KPMG. https://assets.kpmg/content/dam/kpmg/ be/pdf/2019/11/agile-transformation.pdf

Lacity MC, Khan SA, Willcocks LP (2009) A review of the IT outsourcing literature: insights for practice. J Strateg Inf Syst 18(3):130-146

Lee JN, Huynh MQ, Kwok RCW, Pi SM (2003) IT outsourcing evolution: past, present, and future. Commun ACM 46(5):84-89

Lee JN, Miranda SM, Kim YM (2004) IT outsourcing strategies: universalistic, contingency, and configurational explanations of success. Inf Syst Res 15(2):110-131

Leimeister S (2010) IT outsourcing governance: client types and their management strategies. Springer

Mahnke V, Overby ML, Vang J (2005) Strategic outsourcing of IT services: theoretical stocktaking and empirical challenges. Ind Innov 12(2):205-253

Mann A, Folch DC, Kauffman RJ, Anselin L (2015) Spatial and temporal trends in information technology outsourcing. Appl Geogr 63:192-203

Maples C (2009) Enterprise agile transformation: the two-year wall. In: 2009 agile conference. IEEE, pp 90-95

Marcolin BL, McLellan KL (1998) Effective IT outsourcing arrangements. In: Proceedings of the 31st Hawaii international conference on system sciences, vol 6. IEEE, pp 654-665

Mathison S (2005) Cross-case analysis. In: Mathison S (ed) Encyclopedia of evaluation. SAGE Publications Ltd, Thousand Oaks, CA, p 95-96

McIvor R (2000) A practical framework for understanding the outsourcing process. Supply Chain Manag Int J 5:22-36

Mersino A (2018) Agile transformations take too long-a cautionary tale, vol 1. Vitality Chicago. https:// vitalitychicago.com/blog/agile-transformations-take-too-long-a-cautionary-tale/

Meyer AD, Tsui AS, Hinings CR (1993) Configurational approaches to organizational analysis. Acad Manag J 36(6):1175-1195

Miller D (1981) Toward a new contingency approach: the search for organizational gestalts. J Manag stud 18(1):1-26

Nordigården D, Rehme J, Brege S, Chicksand D, Walker H (2014) Outsourcing decisions-the case of parallel production. Int J Oper Prod Manag 34(8):974-1002

Nordström T, Söderström M, Hanseth O (2000) Business development in it-dependent organisations. In: Proceedings of the 23rd information systems research seminar in Scandinavia, pp 77-88

Nutt PC (2008) Investigating the success of decision making processes. J Manag Stud 45(2):425-455

Nutt PC (2011) Making decision-making research matter: some issues and remedies. Manag Res Rev 34(1):5-16

Opelt A, Gloger B, Pfarl W, Mittermayr R (2013) Agile contracts: creating and managing successful projects with Scrum. Wiley

Paasivaara M (2017) Adopting safe to scale agile in a globally distributed organization. In: 2017 IEEE 12 th international conference on global software engineering (ICGSE). IEEE, pp 36-40

Patil S, Wongsurawat W (2015) Information technology (IT) outsourcing by business process outsourcing/information technology enabled services (BPO/ITES) firms in India: a strategic gamble. J Enterp Inf Manag 28(1):60-76

Pattnaik MS, Prusty MR, Dash M (2016) Cloud in financial services: building value across enterprise. Int J Res IT Manag 6(6):25-32

Pratap S (2014) Towards a framework for performing outsourcing capability. Strateg Outsourcing: Int J $7(3): 226-252$

Pries-Heje L, Pries-Heje J (2014) Agile contracts: designing an agile team selection guideline. In: Proceedings/information systems research in scandinavia (IRIS), vol 5

Rajagopalan N, Rasheed A, Datta DK, Spreitzer GM (1997) A multi-theoretic model of strategic decision making processes. In: Strategic decisions. Springer, pp 229-249

Rosing Mv, Scheel Jv, Gill A (2015) Applying agile principles to BPM: the complete business process handbook

Rust RT, Kannan P (2003) E-service: a new paradigm for business in the electronic environment. Commun ACM 46(6):36-42

Saldaña J (2015) The coding manual for qualitative researchers. Sage 
Schoeman S, Bakker N, Borgers M, van Hillegersberg J, Moody D (2008) Bridging the gap between the theory and practice of IS outsourcing strategy design. In: Second information systems workshop on global sourcing: service, knowledge and innovation, 10-13 March, Val D'Isere

Schultze U, Avital M (2011) Designing interviews to generate rich data for information systems research. Inf Organ 21(1):1-16

Simmonds A, Gilmour D (2005) Governance of outsourcing. IT Governance Institute

Smith HA, McKeen JD (2004) Developments in practice XIV: IT sourcing-How far can you go? Commun Assoc Inf Syst 13(1):70

Sohel SM, Quader MS (2017) Transforming IT from a cost centre to a value centre perspective: a case study on the British standards institute. J Serv Res 17(1):71-105

Stettina CJ, Hörz J (2015) Agile portfolio management: an empirical perspective on the practice in use. Int J Proj Manag 33(1):140-152

Su N, Levina N, Ross JW (2016) The long-tail strategy of IT outsourcing. MIT Sloan Manag Rev 57(2):81

Suetin S, Vikhodtseva E, Nikitin S, Lyalin A, Brikoshina I (2016) Results of agile project management implementation in software engineering companies. In: ITM web of conferences, EDP Sciences, vol 6, p 03016

Syed M, Nelson SC (2015) Guidelines for establishing reliability when coding narrative data. Emerging Adulthood 3(6):375-387

Tong A, Sainsbury P, Craig J (2007) Consolidated criteria for reporting qualitative research (COREQ): a 32-item checklist for interviews and focus groups. Int J Qual Health Care 19(6):349-357

Varajão J, Cruz-Cunha MM, da Glória Fraga M (2017) IT/IS outsourcing in large companies-motivations and risks. Procedia Comput Sci 121:1047-1061

Vassiliadis B, Stefani A, Tsaknakis J, Tsakalidis A (2006) From application service provision to serviceoriented computing: a study of the IT outsourcing evolution. Telemat Inf 23(4):271-293

VersionOne (2020) The 14th annual state of agile report, vol 1. VersionOne. https://explore.digital.ai/ state-of-agile/14th-annual-state-of-agile-report

de Vries F, Verkijk P (2017) The impact of DevOps and Agile on outsourcing. Quint Group. https://www. quintgroup.com/en/insights/the-impact-of-devops-and-agile-on-outsourcing/

Webster J, Watson RT (2002) Analyzing the past to prepare for the future: writing a literature review. MIS Q 26(2):xiii-xxiii

van de Weerd I, Brinkkemper S, Souer J, Versendaal J (2006) A situational implementation method for web-based content management system-applications: method engineering and validation in practice. Softw Process: Improv Pract 11(5):521-538

von Bary B (2018) How to bring IT home: developing a common terminology to compare cases of IS backsourcing. In: The 24th Americas conference on information systems, New Orleans, USA

von Jouanne-Diedrich H (2004) Jahre outsourcing-forschung: systematisierung und lessons learned. Konzepte und Strategien für die Praxis 15:125-133

Westphal P, Sohal A (2016) Outsourcing decision-making: does the process matter? Prod Plan Control 27(11):894-908

Yin RK (2017) Case study research and applications: design and methods. Sage

Zijdemans SH, Stettina CJ (2014) Contracting in agile software projects: state of art and how to understand it. In: International conference on agile software development. Springer, pp 78-93

Publisher's Note Springer Nature remains neutral with regard to jurisdictional claims in published maps and institutional affiliations. 


\section{Authors and Affiliations}

\section{Fouad Amiri ${ }^{1}$ (D) Sietse Overbeek ${ }^{1}$ (D) - Gerard Wagenaar ${ }^{1}$ (ID .}

\section{Christoph Johann Stettina ${ }^{2}$ (D)}

Sietse Overbeek

s.j.overbeek@uu.nl

Gerard Wagenaar

g.wagenaar@uu.nl

Christoph Johann Stettina

c.j.stettina@liacs.leidenuniv.nl

1 Department of Information and Computing Sciences, Utrecht University, Utrecht, The Netherlands

2 Leiden Institute of Advanced Computer Science, Leiden University, Leiden, The Netherlands 